\title{
The Impact of Coastal Erosion on Tourism: A Theoretical Model
}

\author{
Francesco Silvestri \\ Department of Communication and Economics, University of Modena and Reggio Emilia, Reggio Emilia, Italy \\ Email: francesco.silvestri@unimore.it
}

How to cite this paper: Silvestri, F. (2018) The Impact of Coastal Erosion on Tourism: A Theoretical Model. Theoretical Economics Letters, 8, 806-813.

https://doi.org/10.4236/tel.2018.85056

Received: February 10, 2018

Accepted: March 25, 2018

Published: March 28, 2018

Copyright (C) 2018 by author and Scientific Research Publishing Inc. This work is licensed under the Creative Commons Attribution International License (CC BY 4.0).

http://creativecommons.org/licenses/by/4.0/

\begin{abstract}
Seashore and coastal areas are the object of human pressure, affecting population well-being and threatening the future economic growth of local communities. To deal with this issue, we discuss an original theoretical model representing the change in tourism demand for a seaside site affected by coastal erosion due to environmental problems. We find out that the decline of the tourist location could occur not only in case of a strong seashore reduction, but even when the coastal erosion still permits tourism demand and satisfactory income for tourism operators.
\end{abstract}

\section{Keywords}

Tourism Modelling, Carrying Capacity, Coastal Management, Tourism-Led Growth

\section{Introduction}

Coastal management and conservation is a top issue in many countries and international organizations, such as UNEP and European Union. Seashore and coastal areas are typically object of human pressure affecting population well-being and threatening the future economic growth of local communities [1] [2] [3]. Nonetheless, the standard approach to coastal management takes origin from the environmental and marine science point of view (eutrophication, water pollution, coastal erosion), and neglects much more the economic perspective. The last one is mostly confined to the elicitation of residents' willingness to pay to contribute to constructing and maintaining coastal defence infrastructures [4] [5], but in just few cases it dealt with optimal development strategy of a tourism destination [6] [7].

What it is really missing in literature is a theoretical modeling of demand and supply reaction to the coastal erosion problem, to address the problem from a 
strategic and a political economy point of view.

This is the main relevance of this work from both practical social side and the academic perspective.

The problems related to seashore erosion are particularly perceived whenever the theoretical carrying capacity threshold is over-passed. The notion of carrying capacity originates in natural science and it depicts the capability of a given habitat to support a particular population, providing the necessary conditions to survival [8] [9]. Other interpretations of this notion led to accept for carrying capacity a multidimensional meaning, different from the strictly physical or "ecological" one: a "social" carrying capacity, identified by the greatest attendance a site could bear without congestion or reciprocal disturbance among visitors; and an "economic" carrying capacity, given by the greatest for-profit activities that could be introduced in a place before saturation, income fall, and economic crisis arise. For each of these three aspect-ecological, social, and economic-does exist a threshold beyond which the site is over-used, triggering a decline trajectory instead of a development one.

Carrying capacity shares this multidimensional approach with another well-known notion, i.e. the sustainability concept [10], but the definitions of sustainable development are copious. This is probably due both to the complexity of the concept, and to its partial "inconsistency", since it tries to keep together different and contradictory elements: development, denoting change and progression, and sustain-ability that recall conservation and status quo protection. From the definition proposed by the Brundtland Report [11], it is well accepted that sustainable development entails an economic element; a deeper interpretation allows to identify in it even an ecological and a social dimension [12], and to get a potential conflict among this three dimensions. As a matter of fact, sustainable development implies to give up the maximization of each sector objectives, for a compromise equilibrium aimed at recomposing the conflict among economy, ecology and social subject.

To discuss this statement we ought to introduce the following diagram (Figure 1).

In this picture, the vertices of the triangle represent the full and theoretic accomplishment of each "sector" target (economic, ecological and social), so that the upper one is a $100 \%$ economic growth objective, while the left one is $100 \%$ of environmental preservation, and the right one is $100 \%$ of social wellbeing. Any movement from a vertex along the sides of the triangle represents a bilateral exchange between a pure tar-get and another. From the ecological to the economic side it means to renounce to strict environmental preservation to accept the benefits from economic growth, for instance building a new motorway to speed up the transport of goods and people or allowing tourism exploitation of a pristine ocean island. From the social to the economic target, it means dealing for instance with the well-known conflict between technological progress and employment protection, or the brand new question arisen by the contrast between 
$100 \%$ Economic target

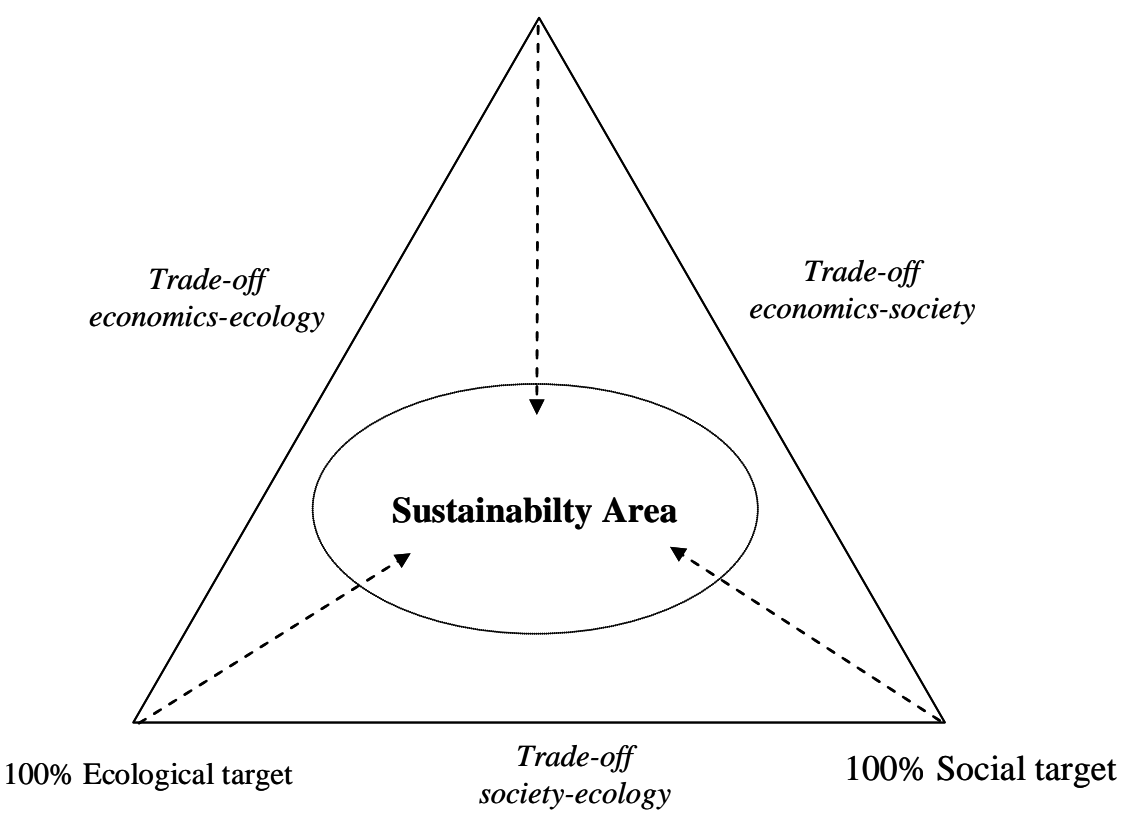

Figure 1. A visual representation of sustainable development (adapted from Munasinghe [13]).

short- and long-supply chain, with the former benefiting peculiar social categories such as consumers and producers, and the latter allowing job creation and value added. Finally, it does exist a trade-off between social and environmental objectives too, emerging whenever individuals must renounce to deep rooted habits, personal or collective rights to take care of environmental issues, such as stop sport-hunting of endangered species, dismissing the use of car to abate air pollution or restricting the access to a visited hotspots to reduce environmental impacts.

The simultaneous renunciation to all three pure targets leads forward the middle of the triangle, in a part of Figure 1 that we call "sustainability area". Arising from mutual trade-off among full objectives, we see that it is a brand new compromise equilibrium, given by the mixture of an achievable part of each of the three sectorial targets. Being very far from a comfortable goal where to keep together the best of each world (environment, production and living society), sustainable development means conscious renunciation and ability to make complex choices.

The Carrying capacity notion interacts deeply with the tourism issue [14]. For sea beaches, in particular, the identification of a capacity is related to the environmental and social externality given by crowd congestion, i.e. the number of tourists concentrated in the site at the same time [15] [16] [17]. Nonetheless, due to climate change and sea-level rise, in last years the congestion externality is worsened by the environmental problem of seashore reduction [6] [18].

The interaction among the different elements of sustainable development and 
among the different kind of carrying capacity thresholds (social, economic and environmental) are the basis of the forecasting model set up to estimate the relation between tourism income and coastal erosion.

To deal with the issue of tourism in seaside location affected by the reduction of carrying capacity threshold, we build a model to forecast tourism demand reaction (Section 2). After we set up, we illustrate the model functioning and the equilibrium conditions (Section 3). Some final lines summarize the main results and conclusions (Section 4).

\section{Environmental, Social and Economic Loss from Coastal Erosion: The Model Set up}

We can describe beach tourism as a market where the demand for seashore surface matches a supply given by the seashore availability.

The beach demand follows a twofold dynamics: on one hand any tourist needs a "living space", a minimal quantity of squared meters on the beach below which the outdoor experience is unsatisfactory; on the other, when on holiday the visitor needs socialite moments, so that an exaggerated room availability, is equally un-satisfactory, being an indicator of boredom and dullness. A general formalization of this attitude could be the following:

$$
\text { seashore demand: } N=G(x-s)\left(1-\frac{x}{e}\right)
$$

where $N$ is the dependant variable, namely the number of attracted tourists; the independent variable $x$ is the available squared meters for each beach user (the "lining space"); $s$ and $e$ are respectively the minimal and maximal threshold below and beyond which representative tourist's individual demand drops to nil (the tourist leave the place because of excess of congestion or because excess of isolation). $G$ is a multiplier, incorporating all the other variables not considered by the model.

The previous formula can be assumed as a social sustainability function, with $\mathrm{s}$ and e as (social) carrying capacity thresholds. From a graphic point of view, in a plan $N=f(x)$ is a parabola with downward concavity and intersection with abscissa in $s$ and $e$ ( $N$ drops to nil for both $x \leq s$ and $x \geq s$ ).

To run the model we need a second function, aimed at identifying the physical seashore availability. This can be draw as follows:

$$
\text { seashore supply: } N=\frac{D}{x}
$$

where $D$ is the seashore extension, and the other variable is the same of the beach demand/social sustain-ability function. Beach supply function, that might be written more correctly in the form $x=D / n$, states that it does exist an inverse relation between the number of tourists that can be hosted on a shore, and the room destined to each of them. Graphically, it is the down-sloped hyperbola branch. This supply function is nothing else but an ecological sustainability 
function, with an upper right point that identifies the physical carrying capacity of the beach.

Assuming fixed prices, economic sustainability can be expressed as the minimal attendance under which the tourism activity is any longer profitable. Taking as reference practitioners' standards and tourism sector vulgate, this threshold is set at the occupancy ratio of $30 \%$ of the total beds endowments. From a mathematical point of view it is a linear function, depicting a straight line parallel to the abscissa and a constant equal to the threshold (see Figure 2):

$$
\text { Economic sustainability: } \bar{N}=0.3 \times P L
$$

where $P L$ is the number of the total beds of all kind of accommodations in the municipality, multiplied for the number of days of the summer season. Drawn in a Cartesian plan, the three functions give the following diagram (Figure 2).

\section{Results: Model Equilibrium}

We can see the equilibrium dynamics in Figure 3: the intersection between supply curve (or ecological sustainability) and demand curve (or social sustainability) identifies the equilibrium, i.e. the number of tourists hosted by the site and the average seashore surface available for each tourist. Whenever the equilibrium is at $N^{*}>\bar{N}$, it is unsustainable from an economic point of view, and supply-side operators leave the market.

Form and position of the parabola reflect characteristics of the representative tourist in each municipality: a moved to the right curve means users more interested to exclusivity; on the contrary, the more it is near to the ordinate axis, the more tourists are concerned with sociality. At the same time, a curve with closer $s$ and $e$ (i.e. a thinner parabola) identifies a less resilient community of tourists, that can more easily leave the place because of a reduction in the individual beach room.

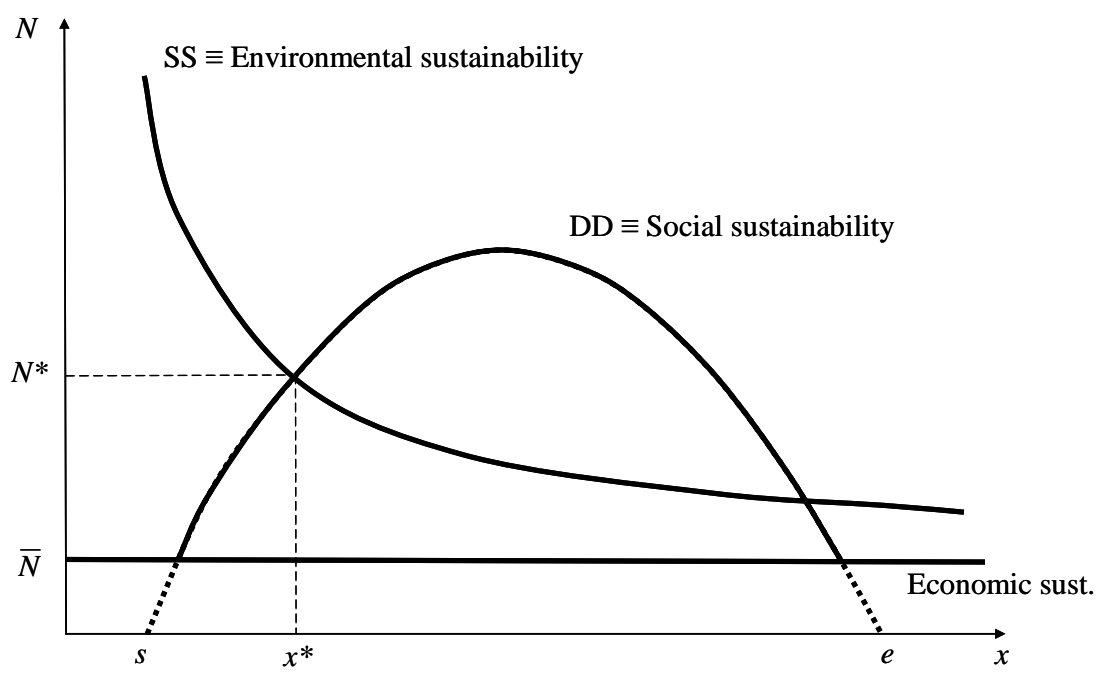

Figure 2. Equilibrium and sustainability in a coastal place with seaside subject to summer tourism. 


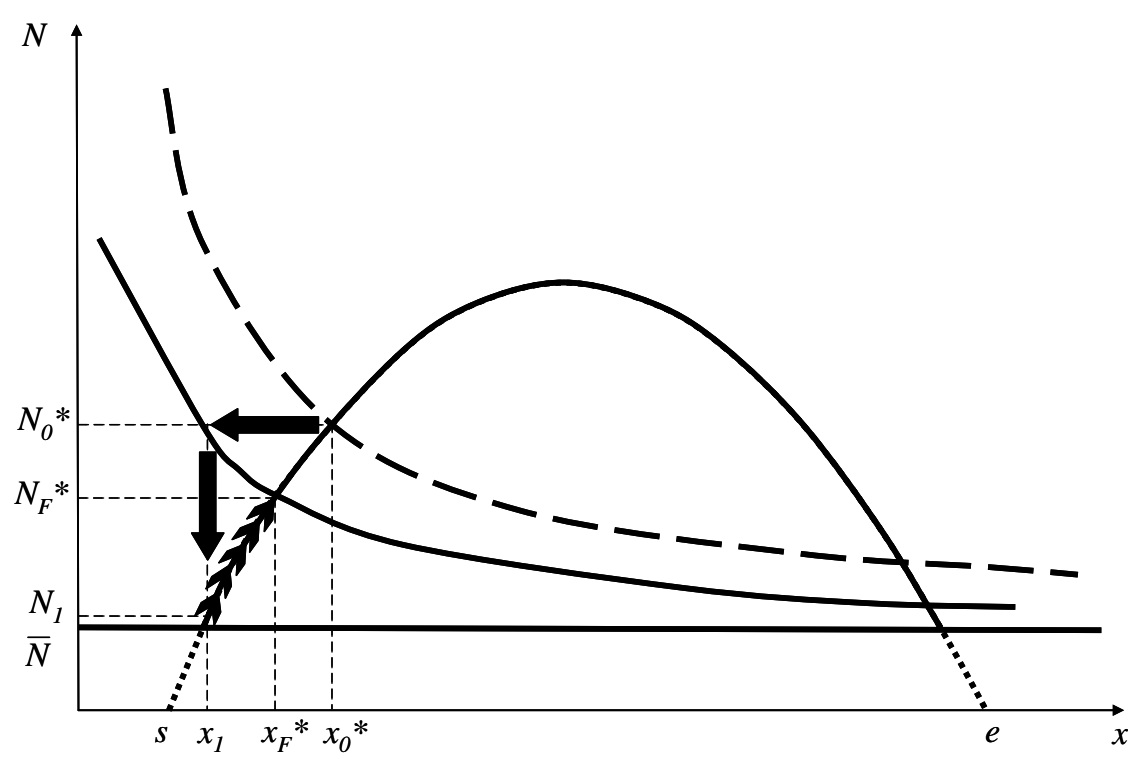

Figure 3. The equilibrium dynamics.

The equilibrium changes along with seashore availability. A downward shift of the supply/ecological sustain-ability curve (reflecting a lower availability of beach, for example because of erosion) locates a brand new spot at the intersection with the demand/social sustainability curve, that does not move. The seasonal character of the tourism experience makes it likely that the system will undergo a shock: initially (from 0 to 1 ), visitors will not perceive the seashore reduction, and the same $N_{0}^{*}$ tourists will keep on attending the beach. But in the new scenario the usable room for each of them has dropped from $x_{0}^{*}$ to $x_{1}$, and when they become aware of the new situation, demand collapse to $N_{1}$. This is not a stable position yet, since the seashore supply is once more different from the perceived one from users. $N_{1}$ visitors have a higher individual room than $X_{1}$, and this attracts new tourists until the point $\left(x_{F}^{*}, N_{F}^{*}\right)$, where the two curves meet again.

In these dynamics, there is an evident problem related to the initial shock: the risk that the decrease of tourists could be irreversible, due to the fact that temporary $N_{1}$ would drop inside the economic non-sustainability area. As we saw, in this case supply operators leave the market and the tourism system crumbles, so that the comeback to $N_{F}^{*}$ does not happen. This means that the decline could spring even for a seashore reduction actually compatible with a tourism exploitation and a satisfactory income.

\section{Conclusions}

In previous pages, we built up a simple model to forecast the evolution of seashore reduction in tourism demand at equilibrium in a seaside location. Working with a limited set of available data on tourism and physical characteristics of seaside places, the model can be a useful instrument to compare the benefits 
generated by coastal protection and shoreline management expenditures, an issue that could affect the optimal development strategy of a tourism destination.

What emerges is that a direct connection does exist between local tourism system income and coastal de-fence investments, so that the latter could be considered as a club good [19]. Since most of generated benefits are of private nature, while coastal defense and managing works are on public sector, the issue claims for a further discussion on a financing scheme that could involve even private operators and companies.

\section{Acknowledgements}

This paper is inspired by the research commissioned by Marche Region for project SHAPE-Shaping a Holistic Approach to Protect the Adriatic Environment between coast and sea, co-funded by EU IPA 2006-2013 program.

\section{References}

[1] Payne, J.E. and Mervar, A. (2010) The Tourism-Growth Nexus in Croatia. Tourism Economics, 16, 1089-1094. https://doi.org/10.5367/te.2010.0014

[2] Balaguer, J. and Cantavella-Jorda, M. (2002) Tourism as a Long-Run Economic Growth Factor: The Spanish Case. Applied Economics, 34, 877-884. https://doi.org/10.1080/00036840110058923

[3] Elofsson, K., Folmer, H. and Gren, I. (2003) Management of Eutrophicated Coastal Ecosystems: A Synopsis of the Literature with Emphasis on Theory and Methodology. Ecological Economics, 47, 1-11. https://doi.org/10.1016/j.ecolecon.2003.09.001

[4] Jones, N., Clark, J. and Malesios, C. (2015) Social Capital and Willingness-to-Pay for Coastal Defences in South-East England. Ecological Economics, 119, 74-82. https://doi.org/10.1016/j.ecolecon.2015.07.023

[5] Peng, M. and Oleson, K.L.L. (2017) Beach Recreationalists' Willingness to Pay and Economic Implications of Coastal Water Quality Problems in Hawaii. Ecological Economics, 136, 41-52. https://doi.org/10.1016/j.ecolecon.2017.02.003

[6] Jennings, S. (2004) Coastal Tourism and Shoreline Management. Annals of Tourism Research, 31, 899-922. https://doi.org/10.1016/j.annals.2004.02.005

[7] Andergassen, R., Candela, G. and Figini, P. (2013) An Economic Model for Tourism Destinations: Product Sophistication and Price Coordination. Tourism Management, 37, 86-98. https://doi.org/10.1016/j.tourman.2012.10.013

[8] Wackernagel, M. and Rees, W.E. (1996) Our Ecological Footprint: Reducing Human Impact on the Earth, Philadelphia.

[9] Prato, T. (2001) Modeling Carrying Capacity for National Parks. Ecological Economics, 37, 321-331. https://doi.org/10.1016/S0921-8009(01)00248-8

[10] IUCN/UNEP/WWF (1991) Caring for the Earth: A Strategy for Sustainable Living, Gland.

[11] WCED (1987) Our Common Future. New York.

[12] Daly, H. (1991) Elements of Environmental Economics. In: Costanza, R., Ed., Ecological Economics. The Science and Management of Sustainability, New York.

[13] Munasinghe, M. (1995) Making Growth More Sustainable. Ecological Economics, 15, 121-124. https://doi.org/10.1016/0921-8009(95)00066-6

[14] Coccossis, H. and Mexa, A. (2004) The Challenge of Tourism Carrying Capacity 
Assessment: Theory and Practice. Ashgate Publishing, Aldershot.

[15] Silvestri, F., Ghinoi, S. and Barone, V. (2013) Nautical Tourism, Carrying Capacity and Environmental Externality in a Protected Lagoon of Northern Adriatic Sea. Economics and Policy of Energy and the Environment, 2013, 145-180.

[16] Mak, J. and Moncur, J.E.T. (1998) Political Economy of Protecting Unique Recreational Resources: Hanauma Bay, Hawaii. Ambio, 27, 217-223.

[17] Mason, P. (2003) Tourism Impacts, Planning and Management. Butterworth-Heinemann, Oxford.

[18] Phillips, M.R. and Jones, A.L. (2006) Erosion and Tourism Infrastructure in the Coastal Zone: Problems, Consequences and Management. Tourism Management, 27, 517-524. https://doi.org/10.1016/j.tourman.2005.10.019

[19] Buchanan, J.M. (1965) An Economic Theory of Clubs. Economica, 32, 1-14. https://doi.org/10.2307/2552442 